\title{
Coastline carrying capacity monitoring and assessment based on GF-1 satellite remote sensing images
}

\author{
Anning Suo, Hongwei Ma, Fang Li, Baoquan Wei, Yong Lin and Jianhua Zhao* (D)
}

\begin{abstract}
The coastline of Zhejiang is the most intensively developed region in China for industry. Based on GF-1 images, an object-oriented classification for coastline was created to monitor coastline exploitation status. A carrying capacity model was then developed to assess the coastline carrying capacity in Zhejiang by means of coastline carrying capacity index (CCl) which is based on coastline artificial parameters and evaluation criterion. The result indicated that coastlines in Cixi, Zhenhai, Fenghua, and Longwan were overloaded with CCl less than 0. The coastlines in Pinghu, Yinzhou, Ninghai, and Dinghai were critically overloaded with CCI ranging from 0 to 0.20 . The other 17 sections with CCl bigger than 0.20 were considered load sections. It can be argued that the overloaded sections and critical overload sections in urban regions should be in primary consideration for protection. This study provided a possible model for coastline management with respect to exploitation and ecological function conservation.
\end{abstract}

Keywords: Coastline, Carrying capacity, Load, Remote sensing image, Assessment

\section{Introduction}

The coastline is not only the boundary line between the sea and the land, but also the transition zone from terrestrial ecosystem to marine ecosystem. It has biodiversity conservation, marine disaster protection, tourist leisure and entertainment, and other ecosystem service functions [1]. Most of the industry of iron and steel, petrochemical engineering, and mechanical manufacture transfer to coastline with global economic integrating in recent decades. This drives large-scale exploitation of the coastline with sea area reclamation, port construction, aquaculture, and other human activities. The exploitation changed coastline landscape and destroyed ecosystem service function of the coastline [2]. The conception of carrying capacity in ecology comes from population ecology. The earliest carrying capacity is the maximum number of individuals living in a specified condition [3]. Malthus introduced the carrying capacity into human ecology and proposed that the resource and environment restrict the growth of population in the end of eighteenth century. Then, he established the basic framework of carrying capacity research based on the logistics model of population carrying capacity [4]. Park

\footnotetext{
* Correspondence: jianhuazhao@yeah.net

National Marine Environment Monitoring Center, Dalian 116023 „China
}

and Burgess gave the definition of carrying capacity from the viewpoint of "capacity" and analyzed the relationship between the carrying capacity and the carrying target in 1921 [5]. Hawden and Palmer transferred the expression of carrying capacity from limited capacity to relative balance capacity based on theory of "balance quantity" and "environmental balance" [6]. The study on the carrying capacity of resource and environment was gradually rising from 1930s; scholars carried a lot of research on land carrying capacity, water resource carrying capacity, tourist carrying capacity, environmental carrying capacity, etc. in agriculture area, typical watershed, wetland, natural reserve and other ecologically fragile areas, and created evaluation methods of net primary productivity estimation, ecological footprint, supply and demand balance, comprehensive index, and system models [7-9]. The carrying capacity research has gradually developed from conception, theoretical analysis to practical application and provided policy guidance for solving problems such as population expansion, resource shortage, environmental pollution, and ecological destruction [10-13].

Marine carrying capacity is the capacity of marine resource and environment carrying human activities in a certain area and period where the structure of regional 
marine resource is consistent with the need of sustainable development, and the function of marine ecosystem still maintains its steady state [14]. The research on carrying capacity of marine resource and environment has aroused the attention of scholars in recent years. William et al. carried carrying capacity research in the Marshall Islands based on the theory of island animal geography balance [15]. Some scholars discussed the relationship between ecological carrying capacity and sustainable development in island from perspective of social demographic factors [16-18]. Jusup and Klanjseek proposed a simulation interaction model between marine biology culture and natural environment in the evaluation of the marine ecological carrying capacity of Cape Bolinao in the Philippines [19]. Cao evaluated resource and environment carrying capacity of Hainan island in 2003-2009 by means of ecological footprint [20].
Some scholars introduced energy analysis into carrying capacity of the uninhabited island [21]. Guan proposed DPSIR theory model to establish evaluating indices system of marine carrying capacity and carried marine carrying capacity evaluation in Jingji marine field [14].

High spatial resolution remote sensing images usually refer to remote sensing images with spatial resolution less than $5.0 \mathrm{~m}$. There have been more than 30 optical commercial high-resolution remote sensing satellites belonging to 13 countries in outer space with rapid development of satellite remote sensing technology since this century. The most representative satellites are IKONOS and QuickBird (USA), SPOT (France), ALOS (Japan), and so on. China began to launch high-resolution series remote sensing satellite (GF series) from April 2013. Seven high-resolution remote sensing satellites are running in outer space at present. The GF series satellite covered from panchromatic,

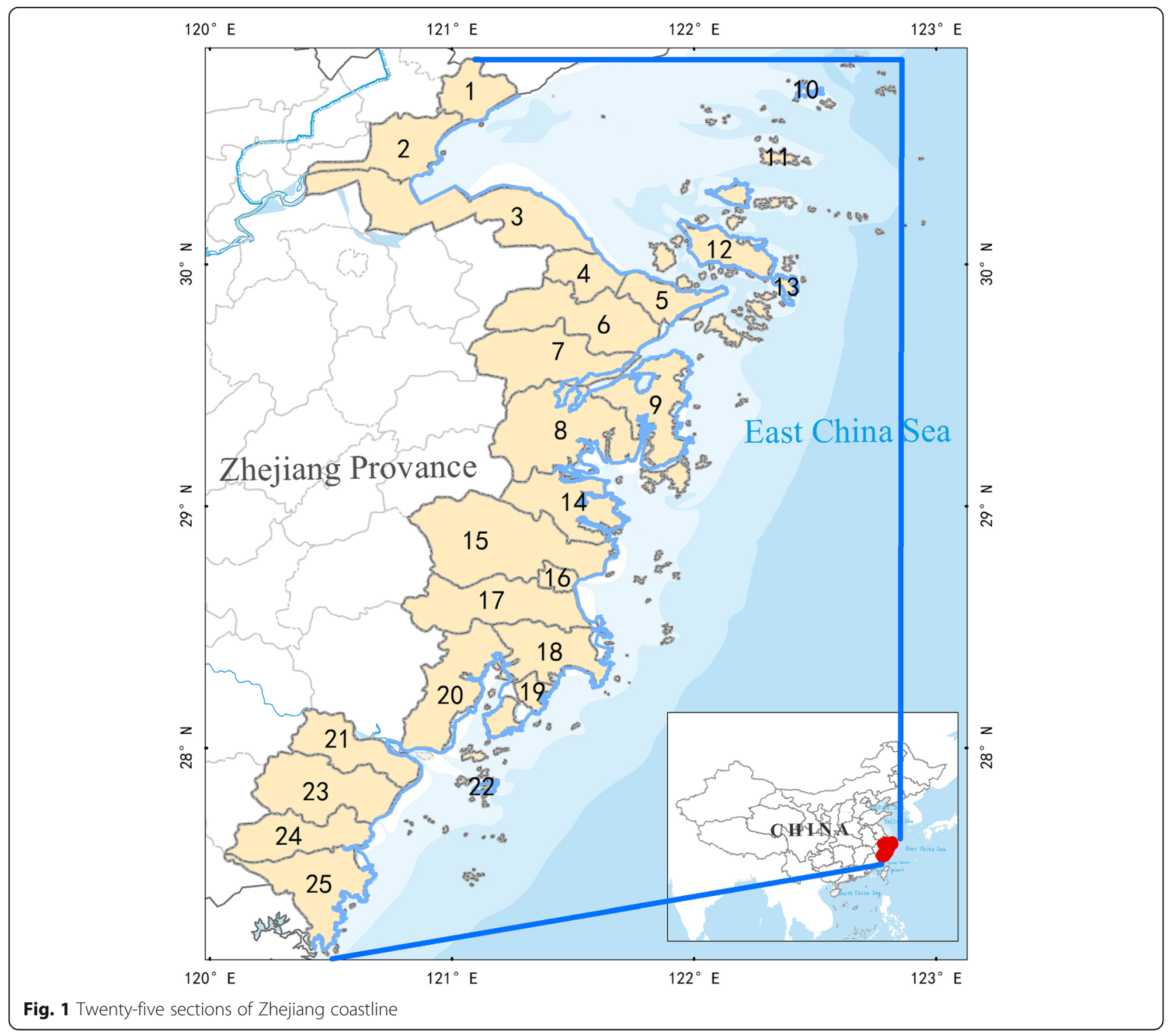


Table 1 Parameter of remote sensing images

\begin{tabular}{llll}
\hline No. & Image type & Resolution $/ \mathrm{m}$ & Obtain time \\
\hline 1 & GF-1 & 2.0 & 2016.05 .16 \\
2 & GF-1 & 2.0 & 2016.05 .17 \\
3 & GF-1 & 2.0 & 2016.05 .19 \\
4 & GF-1 & 2.0 & 2016.07 .25 \\
5 & GF-1 & 2.0 & 2016.07 .26 \\
6 & GF-1 & 2.0 & 2016.06 .17 \\
7 & GF-1 & 2.0 & 2016.06 .18 \\
8 & GF-1 & 2.0 & 2016.06 .25 \\
9 & GF-1 & 2.0 & 2016.07 .26 \\
10 & GF-1 & 2.0 & 2016.06 .20 \\
\hline
\end{tabular}

multispectral to hyperspectral band and formed an earth observation system with high spatial, temporal, and spectral resolution. High spatial resolution remote sensing images are able to identify more detailed information of the shape, texture, and spectrum on land surface. It is the most effective tools for land surface environment monitoring [22]. It can help managers to know the actual situation of coastline carrying capacity by monitoring coastline use and evaluating its carrying capacity. Aimed to reveal regional difference of coastline carrying capacity in Zhejiang, this paper employed GF-1 satellite remote sensing images as basic data and established object-oriented method of coastline monitoring technology. Then, coastline carrying capacity index was created from perspective of coastline management and applied in Zhejiang coastline.

\section{Study areas and methods}

\subsection{Study areas}

Zhejiang coastline, $2021.47 \mathrm{~km}$ in length, lies in east coast of China, south of the Yangtze River estuary. The coastline began at Pinghu connecting Shanghai and end in Cangnan in Wenzhou. The coastline is divided into rock coast, sandy coast, silt coast, and estuarine coast.
The exploitation intensity of coastline is increasing with the development of Ningbo, Taizhou, and Wenzhou, which lies alone the cost, companying the natural coastline changed to port, dam, pond, and other artificial coastline. This destroyed ecological function of the coastline. This paper divided the coastline of Zhejiang into 25 sections according to the local administrative division. The distribution of 25 sections of Zhejiang coastline is shown in Fig. 1.

\subsection{Coastline monitoring data and preprocessing}

This paper collected 10 remote sensing images of GF-1 satellite, which covered all the coastline of Zhejiang clearly. The parameters of these remote sensing images are listed in Table 1. GF-1 remote sensing image has four multispectral bands of B, G, R, and NIR, and one panchromatic band. The panchromatic band pixel resolution is $2.0 \mathrm{~m}$. Because atmospheric rectification and radiation rectification have been processed in satellite ground receiving station, this paper mainly carried the geometric precision rectification as follows: (1) 25 ground control points are evenly set on each satellite remote sensing image, the ground control points mainly choose the intersection of road and dams, which is convenient for the actual location. (2) The ground control points were found by vehicle GPS and surveyed their geographical coordinates by high-precision beacon. (3) Rectification of satellite remote sensing images was carried out by ERDAS IMAGE10.2 refer to the rectification method in relevant literature [23].

The other data include the following: (1) marine function zonation map of Zhejiang province (2011-2020), which is approved by the state council and (2) local administrative division map.

\subsection{Object-oriented coastline monitoring method}

The coastline is divided into natural coastline and artificial coastline according to the completeness of tidal

Table 2 The coastline classification system and their description

\begin{tabular}{|c|c|c|}
\hline First classification & Second classification & Description \\
\hline \multirow[t]{4}{*}{ Natural coastline } & Rocky coastline & $\begin{array}{l}\text { Bed of tidal zone is rock, it formed a curve coastline of harbor and cape by sea level rising } \\
\text { and long process of marine hydrology. }\end{array}$ \\
\hline & Sandy coastline & $\begin{array}{l}\text { Bed of tidal zone is sand and gravel, the particle size of sand and gravel is } 0.063-2 \mathrm{~mm} \text {, it } \\
\text { formed relatively flat coastline by long-term action of waves. }\end{array}$ \\
\hline & Silt coastline & $\begin{array}{l}\text { Bed of tidal zone is silt with particle size } 0.01-0.05 \mathrm{~mm} \text {, it formed open coastline by the } \\
\text { long-term interaction of waves and runoff. }\end{array}$ \\
\hline & Estuary coastline & It is located in estuary and is boundary line of river and marine. \\
\hline \multirow[t]{4}{*}{ Artificial coastline } & Port coastline & It is vertical artificial dikes connecting deep water in port \\
\hline & Industry and town coastline & It is a slope dam connecting industry or town and formed by reclamation. \\
\hline & Dam coastline & $\begin{array}{l}\text { It is a dam located above the highest tidal line to prevent waves, storm tide, and other } \\
\text { erosion. The near region of the dam is nature landscape, usually. }\end{array}$ \\
\hline & Pond coastline & It is a simple dam for aquaculture, sea salt, and other human activities. \\
\hline
\end{tabular}


Table 3 Image characteristics of coastline types

\begin{tabular}{llll}
\hline No. & Coastline type & Spectral feature & Shape and texture feature \\
\hline 1 & Rocky coastline & The water is dark gray and the & The coastline is tortuous \\
land is green with vegetation & with capes and harbor
\end{tabular}

2 Sandy coastline The beach is bright gray between water and land.

3 Silt coastline

The mudflats is dark gray or dark purple

4 Estuary coastline
The coastline is straight with beach in tidal zone

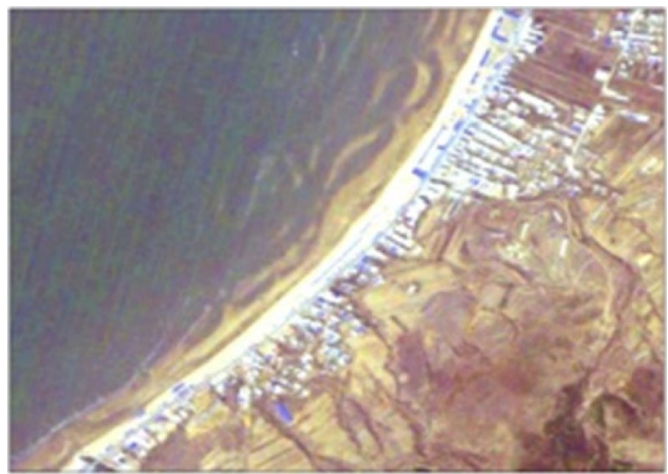

The coastline is natural distribution with height of flats.

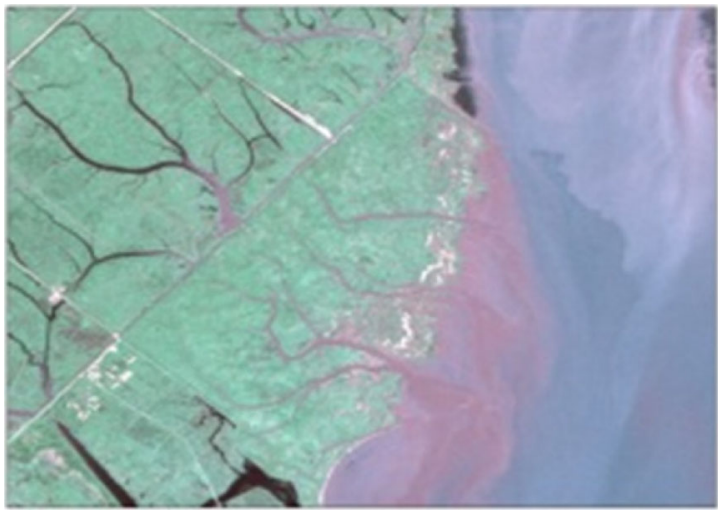

The coastline is boundary of river and marine.

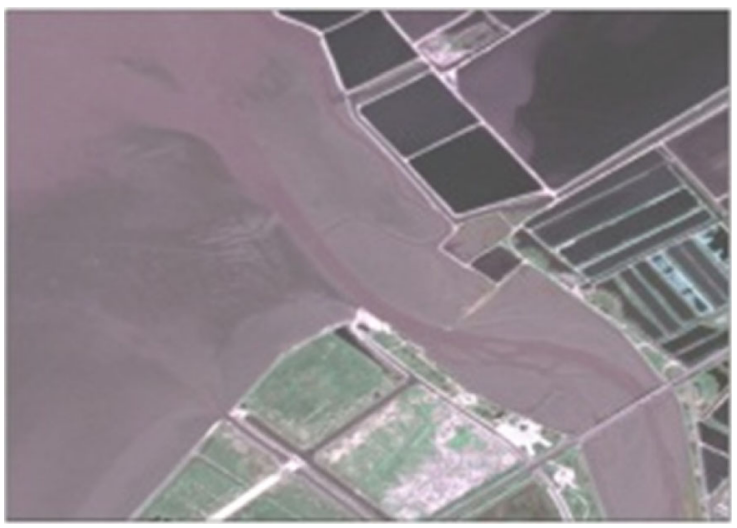


Table $\mathbf{3}$ Image characteristics of coastline types (Continued)

\begin{tabular}{llll}
\hline No. Coastline type & Spectral feature & Shape and texture feature & Image sample \\
\hline 5 & Port coastline & $\begin{array}{l}\text { The water is dark blue } \\
\text { or blue and land is gray. }\end{array}$ & $\begin{array}{l}\text { The coastline is regular } \\
\text { dike and harbor. }\end{array}$
\end{tabular}

6 Industry and The land surface is gray The coastline is town coastline and the water is dark gray. regular and straight.

\section{Dam coastline The dam is bright gray} in natural landscape
The dams coastline is regularly running in natural coast zone
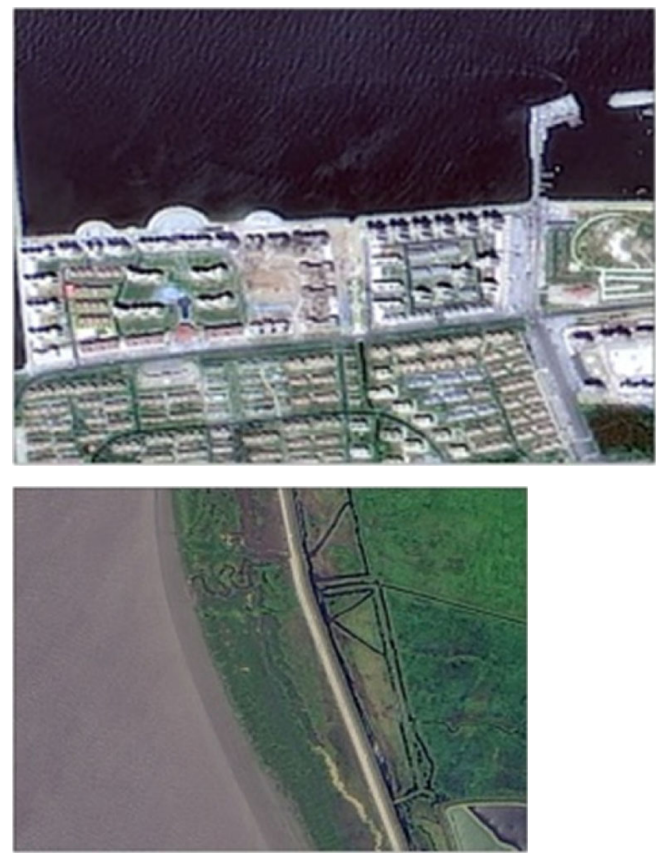

The coastline connecting many ponds of aquaculture of salt.

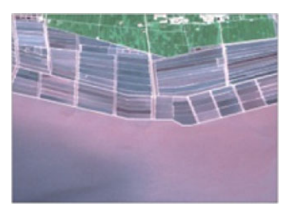

zone. And the natural coastline consists of rocky coastline, sandy coastline, silt coastline, and estuary coastline while the artificial coastline is made up by port coastline, industry and town coastline, dam coastline, and pond coastline. The classification system of coastline is shown in Table 2.

The traditional classification method of remote sensing images based on pixels is not suitable for high spatial resolution remote sensing images for it embodies more abundant information such as texture, spectrum, geometric, etc. Object-oriented classification method is a new way of information extracting for high spatial resolution remote sensing images, which appeared in recent years [24, 25]. This method divided image into scale segmentation and extracts homogeneity region firstly, then analyzed image feature and extracted classification target. It has obvious advantage compared to the pixel-based classification method for the object-oriented method extracts image information in detail from shape and texture of land surface. The object-oriented method is applied in more and more study on high spatial resolution image extracting now. Arroyo applied object-oriented classification to radar and Quick-Bird images to map land cover and estuary shape in coastal zone of the Mediterranean [26, 27]. Platt applied object-oriented method to classify IKONOS image to evaluate the accuracy of land use/land cover $[28,29]$. Cleve and others compared characteristics of pixel classification and object-oriented classification 
using high-resolution aerial images and found that object-oriented method is more suitable for high-resolution image [30, 31].

This paper employed object-oriented classification to extract coastline from GF-1 satellite remote sensing images. First, the GF-1 images were divided into segmentation in suitable scale. Scale segmentation divided the image into pixel group according to the same spectral characteristics and spatial adjacent relations. It can not only generate classification target, but also classify target in hierarchical structure [32]. Then, the spatial image feature library of the coastline was established according to the image spectral features, shape features, and texture features of different coastline type (Table 3). Third, the sample was defined according to the image feature library. And the classifier was inserted to classify image of scale segmentation. Fourth, the ground verification points were collected to test the accuracy of classification; the accuracy of image classification should be more than $90 \%$. The technique flow chart of object-oriented image classification for coastline is shown in Fig. 2.

\subsection{Evaluation of coastline carrying capacity \\ 2.4.1 Coastline artificial index}

The coastline artificial index is calculated as follows:

$$
P_{\mathrm{A}}=\frac{l_{\mathrm{mB}} \times q_{\mathrm{B}}+l_{\mathrm{mT}} \times q_{\mathrm{T}}+l_{\mathrm{mG}} \times q_{\mathrm{G}}+l_{\mathrm{mH}} \times q_{\mathrm{H}}}{l_{0}}
$$

where $P_{\mathrm{A}}$ is coastline artificial index, $l_{\mathrm{o}}$ is total length of coastline(including natural coastline), $l_{\mathrm{mB}}$ is the length
Table 4 Weight of artificial coastline types

\begin{tabular}{|c|c|c|c|}
\hline & Coastline types & $\begin{array}{l}\text { Influence of resource } \\
\text { and environment }\end{array}$ & Weight \\
\hline \multirow[t]{4}{*}{$\begin{array}{l}\text { Artificial } \\
\text { coastline }\end{array}$} & Pond coastline & $\begin{array}{l}\text { Influence is limited and } \\
\text { can be restored }\end{array}$ & $q_{\mathrm{B}}=0.40$ \\
\hline & Dams coastline & $\begin{array}{l}\text { Influence is limited and } \\
\text { cannot be restored }\end{array}$ & $q_{T}=0.60$ \\
\hline & Industry at town coastline & $\begin{array}{l}\text { Influence is great and } \\
\text { most cannot restored }\end{array}$ & $q_{\mathrm{G}}=0.80$ \\
\hline & Port coastline & $\begin{array}{l}\text { Influence is very great } \\
\text { and cannot restored }\end{array}$ & $q_{H}=1.00$ \\
\hline
\end{tabular}

of pond coastline, $l_{\mathrm{mT}}$ is the length of dams coastline, $l_{\mathrm{mG}}$ is the length of industry and town coastline, $l_{\mathrm{mH}}$ is the length of port coastline, and $q_{\mathrm{B}}, q_{\mathrm{T}}, q_{\mathrm{G}}$, and $q_{\mathrm{H}}$ are the weights of above coastline types. They are calculated by statistical analysis from 24 expert opinions and shown in Table 4.

\subsubsection{Evaluation criterion}

The marine functional zonation is key to sea field conservation and utilization management in China. The marine functional zonation divided sea field into eight first-level marine functional zones and 22 second-level marine functional zones. The first marine functional zones include agriculture and fishery zone, port and shipping zone, industrial and urban zone, mineral and energy zone, tourist leisure and recreation zone, marine protection zone, special utilization zone, and reservations [33]. The marine functional zonation clearly defined the location, target, area, and grade for each zone of eight marine functional zone

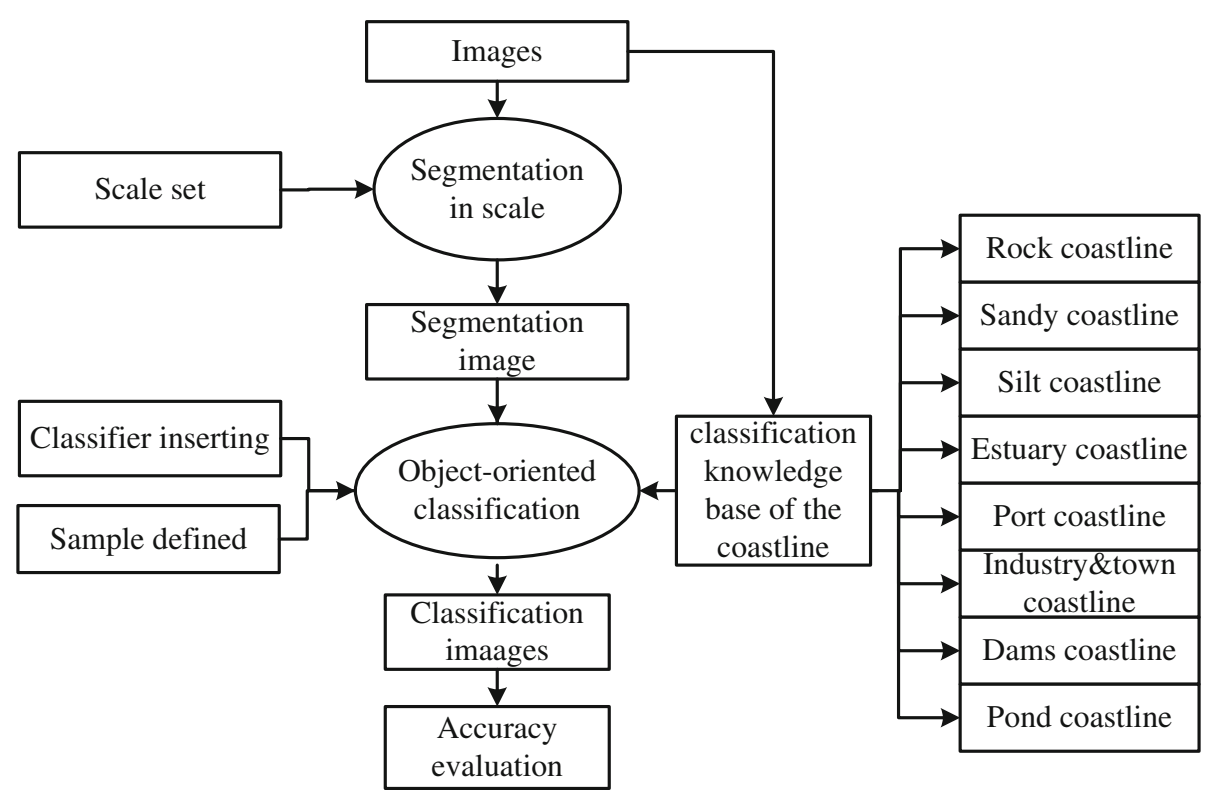

Fig. 2 Technique flow chart of object-oriented image classification for coastline 
Table 5 Marine functional zone and its exploitation intensity

\begin{tabular}{ll}
\hline Marine functional zones type & Intensity factor \\
\hline Port and shipping zone & $w_{i}=0.80$ \\
Industrial and urban zone & $w_{i}=0.60$ \\
Mineral and energy zone & $w_{i}=0.40$ \\
Agriculture and fishery zone & $w_{i}=0.40$ \\
Tourist leisure and recreation zone & $w_{i}=0.30$ \\
Special utilization zone & $w_{i}=0.20$ \\
Marine protection zone & $w_{i}=0.00$ \\
Reservations zone & $w_{i}=0.00$ \\
\hline
\end{tabular}

type. The exploitation intensity factors for each marine functional zone were calculated according to the experts' opinions (Table 5).

The evaluation criterion for coastline was calculated as follow:

$$
P_{\mathrm{C} 0}=\sum_{i=1}^{8} \frac{w_{i} l_{i}}{l_{i}}
$$

where $P_{\mathrm{C} 0}$ is the evaluation criterion for coastline, $l_{\mathrm{i}}$ is the length of coastline connecting marine functional zone $\mathrm{i}$, and $w_{\mathrm{i}}$ is the permit exploitation intensity factor of marine functional zone i.

\subsubsection{Evaluation of coastline carrying capacity}

The carrying capacity of coastline is the space of coastline, and the carrying target is human exploitation activities. So, the coastline artificial index is taken as the carrying target, whereas the permitted exploitation intensity of marine functional zonation is taken as carrying capacity
Table 6 Length of coastline types and its distribution

\begin{tabular}{llrl}
\hline First classification & Second classification & Length & Distribution \\
\hline Natural coastline & Rock coastline & 748.062 & $\begin{array}{l}\text { Cangnan, Xiangshan, } \\
\text { Sanmen, Wenling }\end{array}$ \\
& Sandy coastline & 39.302 & Cangnan, Xiangshan \\
& Silt coastline & 32.529 & Haiyan, Cixi \\
& Estuary coastline & 13.767 & Leqing, Cixi \\
Artificial coastline & Port coastline & 59.875 & $\begin{array}{l}\text { Pinghu, Beilun, } \\
\text { Ninghai, Yuhuan }\end{array}$ \\
& Industry and town & 188.444 & Leqing, Sanmen, \\
& Coastline & & Xiangshan, Zhenhai \\
& Dykes coastline & 117.678 & Cixi, Haiyan \\
& Pond coastline & 821.807 & $\begin{array}{l}\text { Sanmen, Xiangshan, } \\
\text { Cixi, Ninghai }\end{array}$ \\
& & &
\end{tabular}

for evaluation criterion. The model of CCI of coastline is established as follow:

$$
\mathrm{CCI}=\frac{P_{\mathrm{co}}-P_{\mathrm{A}}}{P_{\mathrm{co}}}
$$

where CCI is the carrying capacity index of coastline, $P_{\mathrm{CO}}$ is the evaluation criterion for coastline, and $P_{\mathrm{A}}$ is the coastline artificial index. The $\mathrm{CCI}$ is divided into three categories, namely, load $(S \geq 0.20)$, critical overload $(0 \leq S<0.20)$, and overload $(S<0)$, to express the carrying capacity status.

\section{Result analysis}

\subsection{Coastline utilization}

Zhejiang coastline is $2021.47 \mathrm{~km}$ in length, among which the natural coastline is $833.66 \mathrm{~km}$, accounting for $41.24 \%$. The utilization of coastline in Zhejiang has

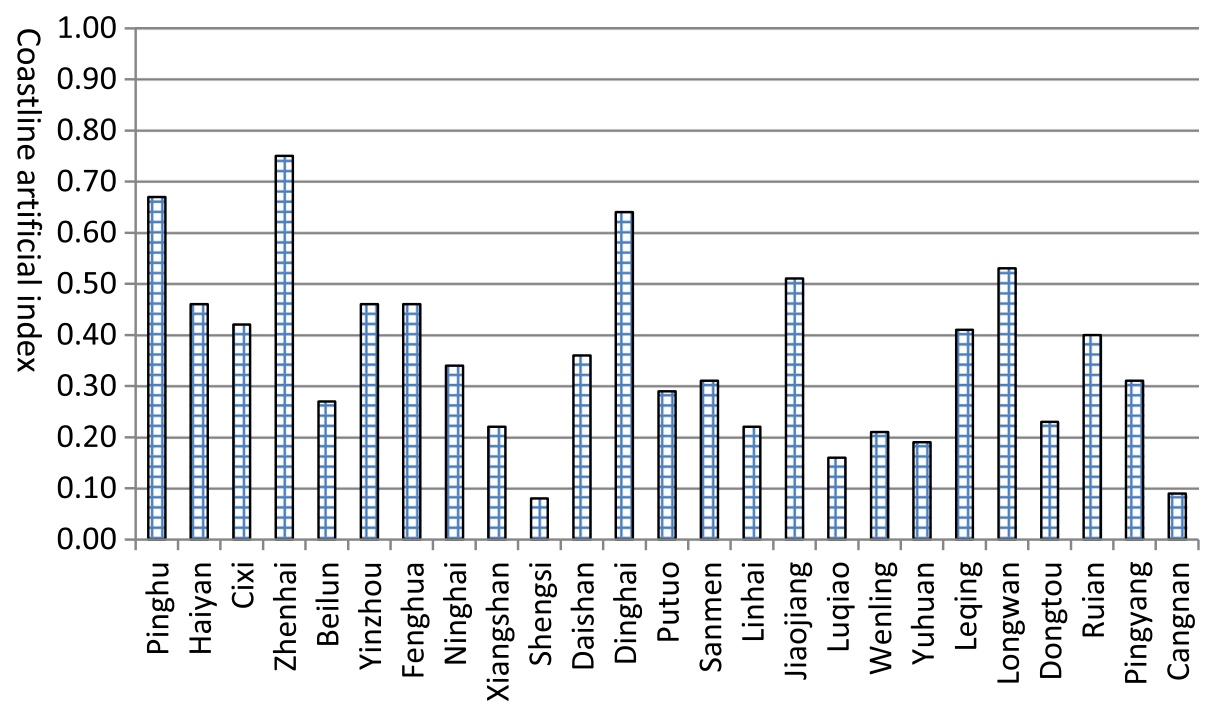

Fig. 3 The coastline artificial index in 25 sections of Zhejiang 
obvious regional difference. The pond coastline is the longest with the length of $821.81 \mathrm{~km}(40.655 \%$ of total length), distributed in Yuhuan, Xiangshan, Sanmen, Ninghai, and Leqing. The industry and town coastline $(188.44 \mathrm{~km})$ ranks second and accounts for $9.32 \%$ of total length, distributed in Fenghua, Zhenhai, Sanmen, and Jiaojiang. The dam coastline is $117.68 \mathrm{~km}$ and mainly distributed in Cixi and Beilun. And the port coastline is the shortest with a length of $59.88 \mathrm{~km}$ and distributed in Beilun and Zhenhai. The lengths of the coastline types are shown in Table 6.

The Formula (1) was applied to calculate the coastline artificial index in 25 sections of Zhejiang coastline, and the results are shown in Fig. 3. The total coastline artificial index was 0.30 in Zhejiang coastline and showed regional difference. The coastline artificial index of Pinghu, Zhenhai, Dinghai, Jiaojiang, and Longwan was above 0.50; it is far bigger than the total index. And the coastline artificial index of Haiyan, Cixi,
Yinzhou, Fenghua, Ninghai, Daishan, Sanmen, Leqing, Ruian, and Pingyang ranged from 0.30 to 0.49 . The artificial index of Beilun, Xiangshan, Shengsi, Putuo, Linhai, Luqiao, Wenling, Yuhuan, Dongtou, and Cangnan were below 0.30 and smaller than the total index.

\subsection{Evaluation criterion index of coastline}

The management coastlines in Zhejiang are shown in Table 7 . The total length of management coastline adjacent to marine functional zonation was $2469.60 \mathrm{~km}$. The coastline adjacent to agriculture and fishery zones, port and shipping zones, industry and town zones, tourist leisure and recreation zone, and reservations zone accounted for $37.71 \%, 25.10 \%, 19.17 \%, 9.83 \%$, and $6.07 \%$ of management coastline, respectively. The coastline connecting agriculture and fishery zones were mainly distributed in Ninghai, Xiangshan, Yuhuan, and Sanmen. The coastline adjacent to port and shipping zones lied in Dinghai, Beilun, Cangnan, and Yuhuan while the

Table 7 The management coastline length adjacent to marine function area of Jiangshu Province. Unit: Km

\begin{tabular}{|c|c|c|c|c|c|c|c|c|}
\hline \multirow[t]{2}{*}{ Sections } & \multicolumn{8}{|l|}{ Zones } \\
\hline & $\begin{array}{l}\text { Port and } \\
\text { shipping }\end{array}$ & $\begin{array}{l}\text { Industry } \\
\text { and town }\end{array}$ & $\begin{array}{l}\text { Minery } \\
\text { and energy }\end{array}$ & $\begin{array}{l}\text { Agriculture } \\
\text { and fishery }\end{array}$ & $\begin{array}{l}\text { Tourist leisure } \\
\text { and recreation }\end{array}$ & Special utilization & Marine protection & Reservations \\
\hline Pinghu & 30.3 & 0.0 & 0.0 & 0.0 & 0.0 & 0.0 & 0.0 & 0.0 \\
\hline Haiyan & 35.3 & 0.0 & 0.0 & 36.4 & 0.0 & 0.0 & 0.0 & 0.0 \\
\hline Cixi & 0.0 & 70.9 & 0.0 & 60.4 & 0.0 & 0.0 & 10.8 & 20.1 \\
\hline Zhenhai & 8.4 & 19.9 & 0.0 & 0.0 & 0.0 & 0.0 & 0.0 & 0.0 \\
\hline Beilun & 74.5 & 0.0 & 0.0 & 0.0 & 15.2 & 0.0 & 0.0 & 0.0 \\
\hline Yinzhou & 1.7 & 6.9 & 0.0 & 13.3 & 0.0 & 0.0 & 0.0 & 0.0 \\
\hline Fenghua & 9.2 & 0.0 & 0.0 & 25.7 & 14.6 & 0.0 & 0.0 & 0.0 \\
\hline Ninghai & 4.7 & 3.6 & 0.0 & 153.5 & 14.6 & 0.0 & 0.0 & 0.0 \\
\hline Xiangshan & 28.7 & 63.9 & 0.0 & 149.8 & 49.9 & 0.0 & 16.5 & 0.0 \\
\hline Shengsi & 0.0 & 14.0 & 0.0 & 8.5 & 33.5 & 0.0 & 0.0 & 0.0 \\
\hline Daishan & 36.3 & 22.7 & 0.0 & 2.4 & 6.4 & 0.0 & 0.0 & 23.0 \\
\hline Dinghai & 91.2 & 5.8 & 0.0 & 8.0 & 0.0 & 0.0 & 0.0 & 4.2 \\
\hline Putuo & 31.6 & 27.6 & 0.0 & 8.6 & 57.3 & 0.0 & 0.0 & 10.5 \\
\hline Sanmen & 38.1 & 55.9 & 25.6 & 94.6 & 0.0 & 0.0 & 0.0 & 16.2 \\
\hline Linhai & 0.0 & 29.0 & 0.0 & 12.7 & 7.4 & 0.0 & 0.0 & 0.0 \\
\hline Jiaojiang & 27.4 & 11.4 & 0.0 & 0.0 & 0.0 & 0.0 & 0.0 & 0.0 \\
\hline Luqiao & 20.1 & 29.5 & 0.0 & 0.0 & 0.0 & 0.0 & 0.0 & 0.0 \\
\hline Wenling & 4.7 & 34.7 & 0.0 & 77.5 & 12.2 & 0.0 & 0.0 & 0.0 \\
\hline Yuhuan & 42.5 & 0.0 & 0.0 & 100.0 & 0.0 & 0.0 & 0.0 & 0.0 \\
\hline Leqing & 37.7 & 40.6 & 0.0 & 48.9 & 0.0 & 0.0 & 0.0 & 0.0 \\
\hline Longwan & 11.9 & 2.3 & 0.0 & 32.6 & 0.0 & 0.0 & 0.0 & 0.0 \\
\hline Dongtou & 7.3 & 7.4 & 0.0 & 26.0 & 0.0 & 0.0 & 0.0 & 15.6 \\
\hline Ruian & 24.4 & 9.1 & 0.0 & 6.6 & 0.0 & 0.0 & 0.0 & 0.0 \\
\hline Pingyang & 10.3 & 11.0 & 0.0 & 6.1 & 0.0 & 0.0 & 0.0 & 0.0 \\
\hline Cangnan & 43.2 & 7.1 & 0.0 & 59.6 & 31.6 & 0.0 & 0.0 & 60.4 \\
\hline
\end{tabular}




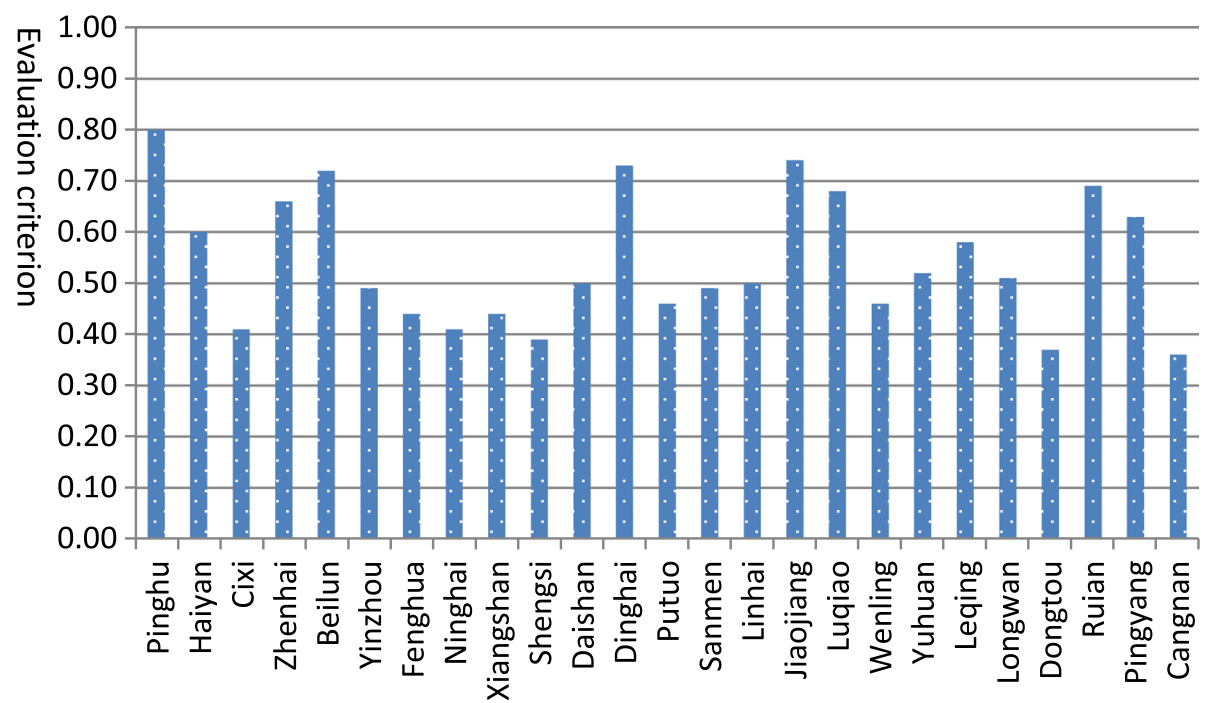

Fig. 4 Twenty-five sections evaluation criterion for coastline of Zhejiang

coastline adjacent to industry and town zones were mainly distributed in Cixi, Xiangshan, Sanmen, and Leqing.

The Formula (2) was applied to calculate the evaluation criterion index of coastline for Zhejiang, and the results are shown in Fig. 4. The values of evaluation criterion index for Pinghu, Beilun, Dinghai, Jiaojiang, Ruian, Luqiao, Zhenhai, Pingyang, and Haiyan were bigger than 0.60. The values for Leqing, Yuhuan, Longwan, Daishan, Linhai, Yinzhou, Putuo, Sanmen, and Wenling ranged from 0.45 to 0.60. Fenghua, Xaingshan, Ninghai, Cixi, Shengsi, Dongtou, and Cangnan had evaluation criterion values less than 0.45 .

\subsection{Carrying capacity index of coastline}

The Formula (3) was applied to calculate the CCI of coastline and shown in Table 8. The CCI is bigger in Cixi (-0.024), Zhenhai (-0.136), Fenghua (-0.046), and Longwan (-0.039) which are classified as overload. The coastlines in Pinghu, Yinzhou, Ninghai, and Dinghai were classified as critical overload with CCI values $0.163,0.061,0.171$, and 0.123 , respectively. The coastline carrying capacity of the other 17 sections are loaded with CCI values above 0.20 . The CCI were bigger in Haiyan, Daishan, and Leqing among these17 sections (Fig. 5).

\section{Results and discussion}

Zhejiang coastal zone is the most developed region in China. The coastline artificialization caused by human activities is highest in regions of aquaculture, reclamation for industry and town, port construction, etc. (1) Aquaculture formed pond coastline. The coast of Zhejiang is the estuary of many rivers such as Qiantangjiang, Oujiang, and
Table 8 Evaluation of exploitation of Jiangshu coastline

\begin{tabular}{|c|c|c|c|c|}
\hline Sections & $P_{\mathrm{A}}$ & $P_{C 0}$ & $S_{1}$ & Status \\
\hline Pinghu & 0.67 & 0.80 & 0.163 & Critical load \\
\hline Haiyan & 0.46 & 0.60 & 0.233 & Load \\
\hline Cixi & 0.42 & 0.41 & -0.024 & Overload \\
\hline Zhenhai & 0.75 & 0.66 & -0.136 & Overload \\
\hline Beilun & 0.27 & 0.72 & 0.625 & Load \\
\hline Yinzhou & 0.46 & 0.49 & 0.061 & Critical load \\
\hline Fenghua & 0.46 & 0.44 & -0.045 & Overload \\
\hline Ninghai & 0.34 & 0.41 & 0.171 & Critical load \\
\hline Xiangshan & 0.22 & 0.44 & 0.500 & Load \\
\hline Shengsi & 0.08 & 0.39 & 0.795 & Load \\
\hline Daishan & 0.36 & 0.5 & 0.280 & Load \\
\hline Dinghai & 0.64 & 0.73 & 0.123 & Critical load \\
\hline Sanmen & 0.31 & 0.49 & 0.367 & Load \\
\hline Linhai & 0.22 & 0.5 & 0.560 & Load \\
\hline Jiaojiang & 0.51 & 0.74 & 0.311 & Load \\
\hline Luqiao & 0.16 & 0.68 & 0.765 & Load \\
\hline Wenling & 0.21 & 0.46 & 0.543 & Load \\
\hline Yuhuan & 0.19 & 0.52 & 0.635 & Load \\
\hline Leqing & 0.41 & 0.58 & 0.293 & Load \\
\hline Longwan & 0.53 & 0.51 & -0.039 & Overload \\
\hline Dongtou & 0.23 & 0.37 & 0.378 & Load \\
\hline Ruian & 0.4 & 0.69 & 0.420 & Load \\
\hline Pingyang & 0.31 & 0.63 & 0.508 & Load \\
\hline Cangnan & 0.09 & 0.36 & 0.750 & Load \\
\hline
\end{tabular}




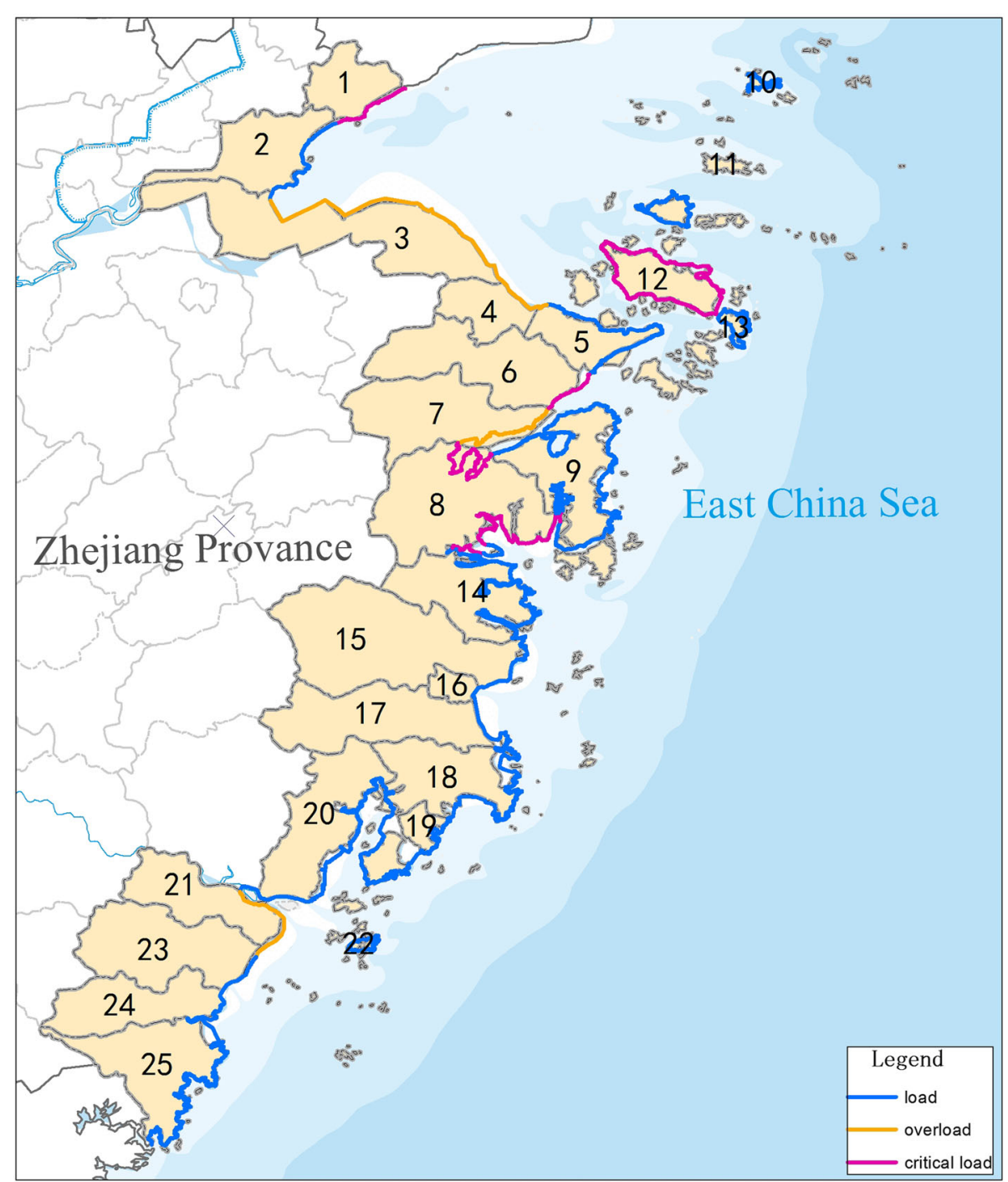

Fig. 5 The carrying capacity grades of the coastline in Zhejiang province

Jiaojiang. These rivers take large sediment from upper watershed and silt up in estuarine forming silt coastline. The silt coastline is very wide with shallow water and suitable for aquaculture and agriculture. So, the most pond coastlines focused on silt coast, and its coastline artificialization was highest. (2) Reclamation formed industry and town coastline. Reclamation is the most popular human activities of coastal exploitation in China in recent years, which circled and filled sea areas and changed it for land for industry and town construction. The reclamation not only changed sea to land, it is also changed natural coastline to artificial coastline and destroyed ecological function of coastline. (3) Port construction formed port coastline. The large port construction changed natural coast landscape to artificial erect coastline. This change not only destroyed ecological function of tidal zone but also cut away ecosystem service of land near coastline. The port coastline in Zhejiang is clustered in large port of Ningbo-Zhoushan.

There is a close relationship between human activities and carrying capacity in coastline. Human activities are carrying object of coastline, such as fishing, reclamation, port construction, etc. It is increased with economic development. Carrying capacity refers to natural space of coastline capacity for exploitation. It is limited in specific time and region. When the human activities scale out limited carrying capacity, the coastline is overload. Otherwise, the coastline is loaded. In Zhejiang province, the carrying capacity that the coastline provided shows regional big difference and varies with marine function zonation. And the intensity of human activities increased and varied in 25 sections in the last 50 years. The aim of 
coastline management is to prevent increased human activities from exceeding the carrying capacity. We hope to control human activities through remote sensing images monitoring and carrying capacity assessment before it was overloaded. Moreover, we can view carrying capacity as goal states and aim to achieve them through active monitoring and management. Generally, the higher coastline artificialization, the bigger carrying capacity index in limited coastline carrying capacity. In the future, we recommend that this model should be applied to the practice of coastline management in China.

\section{Conclusions}

The coastline of Zhejiang is the most intensively developed region in China for industry. Based on GF-1 images, an object-oriented classification for coastline was created to monitor coastline exploitation status. A carrying capacity model was then developed to assess the coastline carrying capacity in Zhejiang by means of coastline carrying capacity index (CCI) which is based on coastline artificial parameters and evaluation criterion. The result indicated that coastlines in Cixi, Zhenhai, Fenghua, and Longwan were overloaded with CCI less than 0 . The coastlines in Pinghu, Yinzhou, Ninghai, and Dinghai were critically overloaded with CCI ranging from 0 to 0.20 . The other 17 sections with CCI bigger than 0.20 were considered load sections. It can be argued that the overloaded sections and critical overload sections in urban regions should be in primary consideration for protection. This study provided a possible model for coastline management with respect to exploitation and ecological function conservation.

\section{Abbreviation}

$\mathrm{CCl}$ : Carrying capacity index

\section{Acknowledgements}

The authors are grateful to the National Natural Science Funds of China (No. 31670468, No. 41501116) and the Leading Science and Technology A, the Chinese Academy of Science (XDA13020401). Thanks to the editor and reviewers.

\section{Funding}

The paper is subsidized by the National Natural Science Funds of China (No. 31670468, No. 41501116) and the Leading Science and Technology A, the Chinese Academy of Science (XDA13020401).

\section{Availability of data and materials}

Data will not be shared; reason for not sharing the data and materials is that the work submitted for review is not completed. The research is still ongoing, and those data and materials are still required by the author and co-authors for further investigations.

\section{Authors' contributions}

AS and HM designed the research. FL, BW, YL, and JZ analyzed the data. AS wrote and edited the manuscript. All authors read and approved the final manuscript.
Consent for publication

We agreed.

\section{Competing interests}

The authors declare that they have no competing interests. And authors have seen the manuscript and approved to submit to your journal. We confirmed that the content of the manuscript has not been published or submitted for publication elsewhere.

\section{Publisher's Note}

Springer Nature remains neutral with regard to jurisdictional claims in published maps and institutional affiliations.

Received: 28 May 2018 Accepted: 28 August 2018

Published online: 12 September 2018

\section{References}

1. D.M. Bilkovic, M.M. Mitchell, P. Mason, et al., The role of living shorelines as estuarine habitat conservation strategies. Coast. Manag. 44(3), 18-26 (2016)

2. A.N. Suo, K. Cao, J.L. Chu, A study on monitoring and analysis of ecological coastline based on GF-1 satellite remote sensing images: a case study in Yingkou. Acta Oceanol. Sin. 39(1), 121-129 (2017)

3. Y.Y. Xiang, J.J. Meng, Research and application advances in ecological carrying capacity. Chin. J. Ecol. 31(1), 2958-2965 (2012)

4. T.R. Malthus, An essay on the principle of population (Pickering, London, 1798)

5. R.F. Park, E.W. Burgess, An introduction to the science of sociology (University of Chicago Press, Chicago, 1921)

6. Hawden S, Palmer L J. Reindeer in Alaska. Bulletin of the U S. Dep. Agric. Bull., 1922, 1089, 1-70

7. J.C.J.M. Van Den Bergh, A framework for modeling economy-environmentdevelopment relationships based on dynamic carrying capacity and sustainable development feedback. Environ. Resource Econ. 3(4), 395-412 (1993)

8. R. Pearl, The growth of populations. Q. Rev. Biol. 2, 532-548 (1927)

9. M. Sleeser, Enhancement of Carrying Capacity Options ECCO (The Resource Use Institute, London, 1990)

10. D.E. Campbell, Emergy analysis of human carrying capacity and regional sustainability: an example using the state of Maine. Environ. Monit. Assess. 51(1), 531-569 (1998)

11. M. Lane, L. Dawes, P. Grace, The essential parameters of a source-based carrying capacity assessment model: an Australian case study. Ecol. Model. 272, 220-231 (2014)

12. J.H. Wang, D.C. Jiang, W.H. Xiao, Assessment method of water resources carrying capacity based on dynamic trial calculation and feedback: a case study on the Yihe River (Linyi section). J. Hydraul. Eng. 16(3), 116-128 (2016)

13. J.F. Yang, K. Lei, S. Khu, et al., Assessment of water resources carrying capacity for sustainable development based on a system dynamics model: a case study of Tieling City, China. Water Resour. Manag. 29(3), 885-899 (2015)

14. D.M. Guan, Z.F. Zhang, Z.X. Yang, et al., Research on measuring of carrying capacity of marine resources and environment. Bull. Chin. Acad. Sci. 31(9), 1241-1247 (2016)

15. I. Williamson, M.D. Sabath, Small population instability and island settlement patterns. Hum. Ecol. 12(1), 21-34 (1984)

16. W.E. Rees, Revisiting carrying capacity: area-based indicators of sustainability. Popul. Environ. 17(3), 195-215 (1996)

17. N. Vernicos, Three basic concepts: man as part of the environment, carrying capacity, conservation. Some further consideration. Econ. Ecosyst. Manag. 14(1), 41-45 (1985)

18. J.D. Yount, Human carrying capacity as an indicator of regional sustainability. Environ. Monit. Assess. 51(1-2), 507-509 (1998)

19. M. Jusup, J. Klanjseek, in Abstracts of EcoSummit 2007: ecological complexity and sustainability: challenges \& opportunities for 21st century's ecology. Estimating ecological carrying capacity for finfish mariculture (Ecological Society of China, Beijing, 2007), p. 210

20. J. Cao, J. Zhang, S.Q. Ma, The analysis of water resource ecological carrying capacity of Hainan international island. Ecosyst. Assess. Fuzzy Syst. Manag. 254(4), 63-71 (2014)

21. Z.W. Zhang, A.P. Feng, P.Y. Li, et al., Carrying capacity of uninhabited island based on energy evaluation: a case of Dachangshan island. Mar. Environ. Sci. 31(4), 562-571 (2012)

22. A.N. Suo, P. Wang, D.W. Yuan, et al., Study on monitoring and analysis of existing sea reclamation based on high resolution satellite remote sensing 
imagery: a case in south coast of Yingkou. Acta Oceanol. Sin. 38(9), 54-63 (2016)

23. T. Wu, Analysis of spatio-temporal characteristics of mainland coastline change in China in nearly 70 years[D]. University of Chinese Academy of Science, 2015

24. S.H. Liu, X.F. Gu, T. Yu, et al, Object-oriented classification method based on GF-1 multispectral remote sensing image. Sci. Surv. Mapp. 39(12), 91-103 (2014)

25. B. Tian, Y.X. Zhou, Z.S. Zhou, Object-oriented image analysis method for estuarine tidal flat accretion and erosion study. Resour. Environ. Yangtze Basin 17(3), 419-423 (2008)

26. L.A. Arroyo, S.P. Healey, W.B. Cohen, et al., Using object-oriented classification and high-resolution imagery to map fuel types in a Mediterranean region. J. Geophys. Res. Biogeosci. 11, 11-19 (2006)

27. X. Jin, C.H. Davis, Automated building extracting from high-resolution satellite imagery in urban area using structural, contextual and spectral information. J. Appl. Signal Process. 14, 2196-2206 (2005)

28. R.V. Platt, L. Rapoza, An evaluation of an object-oriented paradigm for land use/land cover classification. Prof. Geogr. 60(1), 87-100 (2008)

29. A.K. Shackford, C.H. Davis, A combined fuzzy pixel-based and object-based approach for classification of high-resolution multispectral data over urban areas. IEEE Trans. Geosci. Remote Sens. 41(10), 2354-2363 (2003)

30. C. Cleve, M. Kelly, F.R. Kearns, et al., Classification of the wild land-urban interface: a comparison of pixel and object-based classification using high-resolution aerial photography. Comput. Environ. Urban. Syst. 32(4), 317-326 (2008)

31. D. Stow, A. Lopez, C. Lippitt, et al., Object-based classification of residential land use within Accra, Ghana based on Quick Bird Satellite data. Int. J. Remote Sens. 28(22), 5167-5173 (2007)

32. W. Su, J. Li, Y. Chen, et al., Textural and local spatial statistics for the objectoriented classification of urban areas using high resolution imagery. Int. J. Remote Sens. 29(11), 3105-3117 (2008)

33. D.M. Gaun, D. A, Study on national marine function zonation (Marine Press, Beijing, 2013)

\section{Submit your manuscript to a SpringerOpen ${ }^{\circ}$ journal and benefit from:}

- Convenient online submission

- Rigorous peer review

- Open access: articles freely available online

High visibility within the field

- Retaining the copyright to your article

Submit your next manuscript at $\boldsymbol{\nabla}$ springeropen.com 